\title{
The Ambiguous Discourse Participant: Building a Sense of Reader 'Community' in The Sun
}

\author{
Thomas Peter Hawes \\ Sprachenzentrum, Augsburg University, Universitaetsstrasse 2, 86135 Augsburg, Germany \\ *Corresponding Author: tomhawes2004@yahoo.co.uk
}

Copyright (C) 2014 Horizon Research Publishing All rights reserved.

\begin{abstract}
This paper is based on ten consecutive 1991 issues of two Murdoch newspapers in Britain, The Sun and The Times, plus a further ten each from 2008, focusing mainly on editorial articles. All four subcorpora derive from periods in which a UK government, having enjoyed power for an extended period, was visibly weakening and the ideology expressed was, therefore, of some significance. It is claimed that The Sun, the nation's biggest-selling daily, fabricates a sense of reader 'community' by progressively profiling an in-group to be emulated and an out-group to be stigmatised, along with their respective 'values'. What is interesting is that this process in the print media provides opportunities for ideological dissemination without having to overtly adopt a position, yet appears to be aimed at achieving a solidarity analogous to that created orally by 'the word', an official version of reality imposed by a group of indigenous Australian 'fringe dwellers' in Darwin, documented by Sansom (1980). One of The Sun's principal techniques employs discourse participants on a sliding scale of ambiguity to create an impression of solidarity with readers. Discourse participants (eg we, The Sun) are central to this community building as they allow narrators and/or readers to be portrayed as participants in a narrative. They also make it possible to vary writer visibility thanks to a phenomenon we could call referent slippage, or variation in the degree of inclusiveness. Although we can be used to refer unambiguously to the newspaper itself, the referent is often blurred among a) The Sun, b) a specific group of people and c) the entire nation. Disguised participants represent one step further, where they appears to refer to third parties but is, in fact, a dummy referent surreptitiously expressing The Sun's own view. In the past this technique has scarcely been employed in The Times, which tends to thematise abstract concepts and institutions rather than individuals. Nevertheless, The Times is also hesitatingly beginning to employ this device.
\end{abstract}

Keywords Discourse Participant, Writer Visibility, Critical Discourse Analysis, Newspaper Ideology

\section{Introduction}

Newspapers are probably still the most read text types in Britain, if we judge on the basis of volume as opposed to frequency of encounter (since road signs or emails might well be encountered more often). Despite a slow decline in their circulation, popular tabloid dailies sell in large numbers and arguably constitute the nation's preeminent reading matter. Among these tabloids, The Sun stands out in terms of its presumed influence. Selling around three million copies a day, more than any of its rivals, it is arguably one of the nation's most important sites of ideological struggle. While selling considerably less copies per day than The Sun, The Times is arguably still the British newspaper that is most respected and influential with professionals. It was once said by Abraham Lincoln to be the most powerful thing in the world with the possible exception of the Mississippi. This article examines the rhetorical uses of ambiguity in connection with discourse participants, particularly within editorials, and ways in which a newspaper may exploit this ambiguity to help it build a synthetic reader 'community'.

Hodge \& Kress (2006) explain: 'The mass media... construct communication exchanges that bind distant participants into an effective community, so that they can be subject to the effects of power' (2006:46). Far from being a new technique, however, this written strategy appears to mirror a more localised oral tradition possibly dating back millennia. Sansom (1980) studied modality control as exercised by a particular group of indigenous Australian 'fringe dwellers' in Wallaby Cross, Darwin. He documented how one official version of reality, known as 'the word' or 'a straight story', was imposed on the group after a lengthy procedure in which detail was checked and witnesses consulted. Once established, 'the word' had the function of preserving group harmony and allowing the group to speak with one voice. On the other hand, it was forbidden to spread a dissenting version of the facts or to act in a way apparently based on such a version. Anyone doing so could ultimately be excluded from the group (Sansom, 1980, cited in Hodge \& Kress, 2006:151).

The controversial context for these four subcorpora, from 1991 and 2008, is perhaps somewhat parallel. Each series of editorials was published when a government had been in power in Britain for around a dozen years. In each case, the 
Murdoch papers had until then generally supported the government, although in the first instance it was Tory; in the second Labour. In each case, the party in power had at that time already won three general elections, of which the second and third were called early (after four years instead of five). The Tories had won in 1979, 1983 and 1987; Labour in 1997, 2001, and 2005. However, in both instances, the party in power was not expected to win a fourth election and had decided not to hold elections until the full five-year term was up. In both cases there was already talk of the coming election in the media and ideological dissemination was arguably at a premium. This article examines ambiguity and the discourse participant in the four subcorpora. It also looks at whether the relationship between ambiguity and discourse participant has changed in the seventeen years between 1991 and 2008.

\section{Influence on Public Opinion through Role-Modelling}

Impressive claims have been made in recent decades as to the influence that The Sun has over public opinion. After the Conservative victory in the 1992 general election, to which the paper had contributed by a sustained attack on the Labour leader, a headline proclaimed: 'It's The Sun wot won it' (The Sun, 11.4.1992). However, then editor, Kelvin Mackenzie, is said to have received 'the biggest bollocking of [his] life' from its proprietor, Rupert Murdoch (Linton, 1995:15) for running that headline. Whether or not this is true, the owners clearly prefer their influence to be unobtrusive, supporting Fairclough's analysis of public control in the modern world: 'Power does not work negatively by forcefully dominating those who are subject to it; it incorporates them and is 'productive' in the sense that it shapes and 'retools' them to fit in with its needs' (1994:50), and it does this in the context of a 'simulated egalitarianism' (2001:30).

Hawes (2001:400-401) posits an on-going production of symbols through role-modelling, identifying heroes and villains to resolve cultural contradictions and simulate agreement. Reah describes how an 'implied reader' is projected onto the actual reader (Reah, 2002:45). She explains: 'The creation of groups in this way has the effect of implying the existence of a body of opinion... [which] leads the reader to assume that this attitude is shared by a large number of people' (ibid:50-51). Central to this endeavour she cites the differentiated naming of participants. But while naming does undoubtedly contribute to such role modelling, readers may easily become aware of bias when names carry overtly positive or negative connotations.

Therefore, a more effective method would appear to be simply presenting examples of friends and 'others' in positive or negative contexts, respectively, without overtly partial labels. The reader will then be aware of who are or are not 'friends' but have little clear evidence of discriminatory evaluation, which $\mathrm{s} / \mathrm{he}$ might ordinarily wish to resist. Riley (2007:113) refers to this as a membershipping strategy, while
Hodge \& Kress (2006:151) exemplify it by reference to the word in Australian Aboriginal culture. All these elements appear to be present in The Sun's editorials and all, it can be argued, make use of discourse participants. On the other hand, The Times presents a different picture. Its stance is more one of hiding behind information and letting it speak for itself in the hope that the reader will forget that it has of course chosen which information to portray in its texts and which to ignore.

\section{Discourse Participant Themes}

Participant themes are subjects, or 'doers'. They are the norm in most text types. Not only do they represent a majority of all themes, but the choice of a particular participant permits insights into a newspaper's ideology by revealing the sorts of people, groups of people, things and concepts credited with acting on the world or being worthy of discussion. Since the most noticeable of these participants are human, and since we identify most readily with fellow human beings, this introduces a 'personalist' element of solidarity. Hill (2007), writing in an American context, clarifies thus: 'Media discourse in the United States serves elite interests by reproducing a language ideology that is often called "personalism"' (Hill, 2007:70). This can provide a bridge between public power and the private individual-reader, blurring the line between these domains. Moreover, it permits what Talbot, Atkinson \& Atkinson call 'the construction of a friendly persona' with the help of pronouns "we" and "you". The writer is "represented as the reader's friend and as knowing what the reader thinks... claiming common ground and a social relation of closeness' (2003: 26, 29).

Varying the frequency of occurrence of a participant type present in a text, whether named (eg Gordon Brown), title (the Prime Minister), pronoun (he), or institution participant (the Labour Party), alters the ideological perspective. The choice of a discourse participant as theme denotes a writer's personal intervention in the discourse. This typically takes the forms we, our, us, or The Sun. It often portrays the paper as a sentient being, eg with the verbs 'feel' or 'think'. Discourse participants allow the newspaper to assume the mantle of human friend and adviser, rather than being a mere commodity. The examples below are found in a 1991 article in The Sun exposing Southern Electric's shabby treatment of a customer. The discourse participants are italicised:

An executive brushed the incident off as a rare and inexplicable fall from usual high standards. The Sun feels this is one case that cannot be brushed aside. We have never been more delighted to wash dirty linen in public (The Sun: 14.10.91).

As no British newspaper editor is likely to employ the first person singular pronoun $(I)$, this is the closest one can find to direct personal participation in the discourse. Therefore, in the sense of putting one's journalistic reputation where one's mouth is, any statements organised around the thematisation 
of discourse participant subjects are particularly bold.

Davies (1990) posits a visibility continuum of higher or lower profile writer stances. At one end of this continuum is the open directness of a discourse participant theme (eg 'The Sun feels...'), through which the writer may present her/himself as subject in theme position. At the other end is the invisible author of a predicated IT theme (eg 'It is the case that...'), which presents things as established fact and 'relieves the writer of any responsibility for the viewpoint' (Davies, 1990:15).

Davies claims that the use of a discourse participant leaves no doubt as to whose views are being put forward. This may hold for her academic discourse. However the situation is more complex in newspapers, which do not necessarily 'play by the rules'. Discourse participants can clarify who is speaking (as in The Sun) but editors may prefer to opt for ambiguity. Thus, we might be exclusive to the newspaper, or inclusive of others. If inclusive, we could mean 'you the reader and I the editor', or one of many other possible combinations. It may not be obvious to the reader when the paper switches between the inclusive and exclusive options and the line between them may become blurred.

\section{Data, Model, Methodology}

\subsection{Data}

This research is based on four separate data collections, each of ten consecutive issues of the British newspapers The Sun and The Times, from 10-21 October 1991 inclusive and 8-18 September 2008 inclusive, respectively. The 1991 subcorpus comprises 60 individual editorial articles, while that of 2008 comprises 61. Discourse participant statistics are based only on these editorial articles, but the rest of the paper is also consulted as context.

\subsection{Model}

Thematisation is the structuring of a clause into two parts. The theme, or leftmost part, usually situates the various elements in the context as 'given' or at least retrievable information, while the rheme, or rightmost part, normally implies 'new' propositions and comment. Through the choice of elements as either theme or rheme a writer can present notions as more or less taken-for-granted or, alternatively, something to be discussed and perhaps even questioned. Halliday's (1985) seminal definition of theme can be glossed as 1. the start of the clause, 2. everything up to and including the first ideational element, and 3 . what the message will be about.

\subsection{Methodology}

The analytical procedure was, briefly: 1. locate and number each independent clause or clause complex; 2 . identify a theme for each one; 3 . determine the numerical importance of each theme category under consideration, especially discourse participants; 4 . count also discourse participants in rheme; 5 . analyse similarities and differences between categories in the 1991 and 2008 corpora against various criteria, eg their position within Hoey's (1983) Problem-Solution pattern; 6. compare their pragmatic uses and formulate hypotheses as to their rhetorical motivation.

\section{Findings}

\subsection{Findings (1): 1991}

Eleven discourse participants in 1991 account for 5\%, or one in twenty, of all themes in The Sun's editorial articles. If this seems a relatively small number, it should be remembered, firstly, that they are only one among several types of participant theme, and that there are also numerous non-participant theme types. Secondly, $5 \%$ is fifty-fold the tally in The Times, where there is only a single instance of a discourse participant in nearly a thousand themes (1/945, i.e. $0.1 \%)$ in 1991. The Sun's discourse participants therefore occur relatively frequently and this is unlikely to be purely by chance. Therefore the editor of The Sun is incomparably more visible than the editor of The Times, who may seem non-existent as far as wishing to persuade the reader goes, as if the text writes itself and is merely there for consumption.

Discourse participants provide a podium for statements of position that are unusually direct when compared to statements using other grammatical subject types. They thematise the writer or the paper itself (we or The Sun) intervening as agent, or else the whole community (we representing any group up to and including the nation). This exclusive/inclusive divide can be illustrated by the following examples. The first, already cited above, is exclusive (i.e. referring exclusively to The Sun). The second is inclusive, but vague as to precisely who is included. It seems to imply, perhaps surprisingly, that the newspaper has authority to speak on behalf of the entire country:

1. We have never been more delighted to wash dirty linen in public (The Sun: 14.10.91);

2. We should arrange [Commonwealth Conferences] only every four years, like the Olympics (The Sun: 21.10.91).

Whether a discourse participant refers to writer, paper or community, the one constant is the centrality of The Sun itself, in 1991 generally in the role of adviser. This centrality is so marked that one is almost tempted to suggest 'discourse hero' as a more appropriate label than 'discourse participant'.

Two thirds of discourse participants unambiguously refer to the paper itself and its own positions. All are outspoken and most constitute direct attacks on individuals or institutions. In one case, The Sun takes up a complaint by the sports commentator Frank Bough that car boot sales cause traffic jams and, by leaking some information supposedly relevant to the issue, turns what is arguably non-news into 
both a defence of free trade and an attack on non-conventional life styles or a perceived lack of 'values':

[Frank Bough] complains, people selling rubbish cause traffic jams. This is the same $\mathrm{Mr}$ Bough who once consorted with prostitutes and took cocaine. We infinitely prefer the habits of people innocently buying and selling to his own sordid behaviour... (The Sun: 15.10.91).

With the help of discourse participant we, in this example, The Sun effectively by-passes any serious level of reasoned argument, ignoring the issue raised by Bough, and aims straight for the opponent's weak point. The crass line of argument could be summarised as 'You are worse, so keep quiet!'

The next example does not initially look so much like an attack. The rheme of the discourse participant theme expresses support for the Tories, in the person of Douglas Hurd. However, it is primarily an assault on the notion of a federal Europe, one of The Sun's long-standing bogies. Note that, in terms of text progression, the discourse participant is used to break with the preceding sequence, condemning Ted Heath's alleged divisiveness, and sets up a new sequence on the subject of anti-European party unity and the coming spring 1992 elections. This is possible because a discourse participant steps into the text from outside (ie, it is exophoric) and usually has no link back to a previous theme or rheme. It is outside the scope of Daneš' thematic progressions and can therefore be employed to take the text in a new direction:

Ted heath believes that nothing good has happened since 1974 [when he lost the leadership of the Tory party to Margaret Thatcher]. He even blames privatisation for the murder of the bandsmen at Deal. To return to reality, we welcome Douglas Hurd's hostility to a federal Europe. This places the Government in harmony with Mrs Thatcher... (The Sun: 10.10.91).

The remaining third of discourse participants that purport to speak for the community or the nation all carry ideologically charged positions. The instance above relating to Commonwealth Conferences is a typical example and it is the more forceful by virtue of being the final clause of its editorial article and, moreover, underlined in the original. The Sun not only equates itself here with the nation but apparently presumes to speak for the government itself, even for a range of (Commonwealth) governments.

In a final example from 1991 of an inclusive discourse participant used to attack 'others', The Sun becomes downright insulting. At the end of an article describing how the con-man Keith Cheeseman tricked two High Court judges, the latter are likened to donkeys. It is another instance of the paper using even the inclusive form of discourse participant - we being here a general term, embracing the nation rather than an explicit podium for The Sun's views - in an overtly rhetorical manner:

The law may be an ass, but we've certainly got some donkeys on the bench (The Sun: 18.10.91).

Further evidence that The Sun's discourse participants are important to its ideological dissemination is linked to where they occur within the narrative structure of a text. Analysis against Hoey's (1983) Problem-Solution pattern (essentially the sections Situation-Problem-Solution-Evaluation), for instance, produces the following results:

Table 1. Human participant themes in The Sun by Problem-Solution section

\begin{tabular}{|c|c|c|c|c|}
\hline & Situation & Problem & Solution & Evaluation \\
\hline $\begin{array}{c}\text { Discourse } \\
\text { Participant: }\end{array}$ & $3 \%$ & $5 \%$ & $6 \%$ & $8 \%$ \\
\hline Named Participant: & $26 \%$ & $13 \%$ & $14 \%$ & $5 \%$ \\
\hline Title Participant: & $10 \%$ & $3 \%$ & $4 \%$ & $3 \%$ \\
\hline $\begin{array}{c}\text { Institution } \\
\text { Participant: }\end{array}$ & $19 \%$ & $23 \%$ & $36 \%$ & $14 \%$ \\
\hline
\end{tabular}

The highest frequency of occurrence of named participants is in Situation, ie the early stages of a text (where they account for $26 \%$ of all themes), with their lowest frequency being towards the end, in Evaluation (5\%). Title participants show a similar pattern, declining in frequency from Situation (10\%) through to Evaluation (3\%). Exactly the opposite trend holds for discourse participants, which occur least often in Situation $(3 \%)$ and most often in Evaluation (8\%). Since Evaluation is the section most closely associated with authorial opinion, this supports the notion that discourse participants are closely allied to the function of building a sense of reader community.

The Times' lone discourse participant in the 1991 subcorpus is not employed to make an ideologically engaged statement. Having discussed various changes in pub culture up to the present time, it merely serves to continue the review and stands for Britain as a whole:

Now we are in the middle of a third and more diffuse revolution. There is the pub as entertainment centre, with live music... (The Times: 17.10.91).

\subsection{Findings (2): 2008}

By 2008 things have developed somewhat surprisingly. On the one hand, The Sun has generally chosen to disseminate its ideology more indirectly and there is no longer any question of headlines in the vein of "It's The Sun wot won it". On the other hand, the use of discourse participants has increased as a proportion of all themes. From $5 \%$ in 1991 , they have more than doubled, to $12 \%$ of all themes, in 2008. What is more, the ambiguity appears to be more systematic. A relatively bigger change has occurred in The Times which, while still employing far less than its sister paper, now has six times more discourse participants than it did in 1991 (6/941, approaching 1\%), suggesting that it is hesitatingly moving down-market and following at least one tabloid trick.

In The Sun a fascinating reversal has taken place between 1991 and 2008. Whereas in 1991 two thirds of discourse participants unambiguously referred to the paper itself and 
only one third were ambiguous, the 2008 figures are completely different: only $16 \%$ (6), or less than one in six, of discourse participants, clearly denote the paper itself, while $84 \%$ (32), or more than five sixths, refer ambiguously to some group or the nation. This underlines the trend towards ambiguity and a less straightforward dissemination of the paper's ideology. Table 2 presents the totals for The Sun. Figures in brackets stand for the number of discourse participants occurring in the respective subcorpora; percentages show what proportion of all themes these represent.

Table 2. Discourse participants in The Sun by date and ambiguity

\begin{tabular}{|c|c|c|c|}
\hline & TOTAL & THE SUN & AMBIGUOUS \\
\hline 1991 & $5 \%(11)$ & $3 \%(7)$ & $2 \%(4)$ \\
\hline 2008 & $12 \%(38)$ & $2 \%(6)$ & $10 \%(32)$ \\
\hline
\end{tabular}

Instead of openly claiming to win elections, The Sun now plays down any influence it may have on the electorate, while at the same time emphasising its influence with the government. This takes the form of portraying itself as nudging government policy in the 'right' direction by providing politicians with vital information. In other words, its self-proclaimed role is akin to that of a 'patriotic' citizen. Two excerpts below come from the 13.9.08 edition of the paper, but are not from editorials and are thus not counted in the statistics. The second discourse participant is noteworthy because it occurs in rheme, rather than in theme. The first excerpt shows The Sun playing a part in the so-called 'war on terror'. Note also that the initial discourse participant theme is unusually specific and cannot be accused of promoting ambiguity, but that it gives newspaper reporters a theatrical role, as if they were combatants in a suspense thriller:

Undercover Sun investigators secretly recorded [an islamist] telling a young and impressionable audience that they would eventually rule under strict Sharia law... Last night Scotland Yard asked The Sun for a copy of our video showing Choudary and Islam's rants. Cops from SO15, the Yard's Counter-Terrorism Command, will study the footage (The Sun: 13.9.08, p.12, non-editorial).

The second extract exemplifies the paper's on-going concern with crime and morality and relates to a Halloween-style party for the inmates of Holloway Prison, twice mentioning The Sun's role in prodding the Government into action:

Jack Straw BANNED jail parties yesterday after The Sun told how women killers held a sick Monsters' Ball. Mr Straw acted after we published chilling pictures of more than half a dozen vicious murderers at a gruesome fancy dress party... (The Sun: 13.9.08, p.15, non-editorial).

What is perhaps most different about The Sun in 2008 is that it no longer overtly campaigns for a political party. In late 1991 its strategy was to directly attack the Labour leader Neil Kinnock, while The Times indirectly bolstered support for John Major's Tories. But, having helped the Conservatives to retain power in 1992 and then regretted it very publicly in January 1994 under the title 'What fools we were', The Sun appears to have learnt a lesson. It has recently lent support only to its own preferred position on any given issue, without necessarily referring to a political party - though of course this could change.

In The Sun of 2008, the method chiefly employed is to create the illusion of a 'community' of readers who are solidly behind a particular stance. This is achieved by repeatedly focusing on given celebrities and, thereby, progressively profiling an in-group, comprising supporters of The Sun's own position, and an out-group who are to be stigmatised. This method resembles a written discourse version of gossip, where the merits of one individual or group after another (and, by implication, their ideas) are discussed. It provides opportunities for ideological dissemination without having to overtly adopt a party political position.

Unlike The Sun, The Times does not employ discourse participant in any of the above strategies. Instances in The Times essentially consist exclusively of generic we, representative of the whole community/group, as in the following:

Among the defining features of the human animal is a unique capacity for contemplation... We wish to understand not only the world around us, but also its origins (The Times: 8.9.08).

Two borderline exceptions to this pattern really only serve to prove the rule. The first is a deliberate misspelling at the start of an article on grammar/spelling and may be considered a joke:

Wee belive thet its practise thet maks grandma prefect [sic] (The Times: 15.9.08).

The second is a more specific case but is not a linguistic choice on the newspaper's part. Rather, it is a direct quote from the then British transport union leader, Jack Jones, whose we refer to his union colleagues and himself. Thus, while it employs more discourse participants in 2008 than it did in 1991, The Times remains distinctly conservative in the way it uses them.

\section{3. Referent Slippage}

A potential rhetorical strategy at a writer's or paper's disposal is to exploit Davies' abovementioned visibility continuum, using discourse participants to vary the writer's visibility and also the specificity of the referent, so that what is strictly the paper's opinion may seem to be endorsed by a whole reader 'community'. This device is not employed in The Times but is significant in The Sun. Not only is it more frequently used in The Sun in 2008 than it was in 1991, but the ambiguity is also more extensively exploited. Discourse participants in The Sun now show signs of slippage from one extreme of the spectrum (referring unambiguously to the 
paper itself), to the other extreme (where we can be anything up to and including the whole country). An example with a transparent referent is:

The Sun will be watching to make sure energy

firms don't pass on the costs (The Sun: 12.9.08).

At the opposite end of the spectrum, an example of multiple slippage in the referent of we can be found in an article on a scientific experiment involving the Large Hadron Collider. The first discourse participant theme of the article is already unclear as to its referent and could pertain to the editorial board, but could also refer to the newspaper's readers or any group up to and including the nation:

We shut our eyes and counted down the seconds.

The clock ticked (The Sun: 11.9.08).

As for the second, it is even less clear because it appears to extend its scope still further with the word 'all':

We were all still here (The Sun: 11.9.08).

A third discourse participant we appears to refer to The Sun's reader 'community'. The paper seems somewhat presumptuous, for, not only does it purport to speak on behalf of many people it does not actually know, but it admits to a failing or lack of knowledge on their behalf:

But mostly we just didn't understand what was going on (The Sun: 11.9.08).

In the final clause of the article, the discourse participant slips back again in scope to being limited to The Sun itself:

What does it all mean? If we knew, we'd tell you (The Sun: 11.9.08).

The use of such referent slippage clearly holds potential for manipulation of the reader, if not for outright mystification. In a last example, below, two discourse participant themes demonstrate the ideological force of such blurring. The slippage from the paper itself to the whole country is so abrupt, and the implied association between The Sun and the nation so strong, that an uncritical reader might be forgiven for forming the impression that the paper's staff are personally fighting and dying. This time the excerpt on Islamists is from an editorial article:

In London, The Sun films Islamic fanatic Anjem Choudary ranting that Muslims must take over Britain and bring in sharia law. We are at war in Afghanistan (The Sun: 13.9.08).

\subsection{Disguised Discourse Participant}

A final device found in The Sun but not The Times is a discourse participant type we could call 'disguised', where for example the pronoun they, referring to some unashamedly fictitious third parties, is in fact a dummy participant, expressing The Sun's own view. An example of this is:

LEWIS Hamilton and Andy Murray showed true Brit grit yesterday... They call it the bottle of Britain (The Sun: 8.9.08).

On the face of it, Hamilton and Murray exemplify The Sun's role-modelling of military and sports 'heroes' (Hawes, 2010:8; Reah, 1998:37-45), commended for their courage in the face of seemingly superior opponents. However, their accomplishments are described in language more reminiscent of World War II than of an amicable sporting event, suggesting that the paper's real motivation lies deeper than this. The disguised discourse participant they is so blatant a rhetorical device that it seems in this case the newspaper is proudly and deliberately drawing attention to its real agenda.

The agenda behind the 'bottle of Britain' appears to be revealed in The Sun's 'Striker' comic strip, which confirms its continuing anti-Europeanism and nationalism. The story in 'Striker' revolves around a German footballer and his wife, whose accents strongly recall the 'German' accents used by the villains in old World War II movies. An example from the 11.9.08 issue of The Sun is:

Nein - ve are ze victims... zat is vot zer police vill find out... (The Sun: 11.9.08:44, non-editorial).

If there is a more specific agenda here it is arguably one of keeping Britain's alliance with the USA as its priority in foreign affairs, but its involvement with the EU to a minimum. This could tie in with the fact that the Murdoch media empire has for some time now been based in America.

\section{Conclusions}

The use of discourse participants in the editorials of both The Sun and The Times increased between 1991 and 2008. In the former, if not in the latter, it has assumed a major role. Prima facie, this development is linked to the simulation of a dialogic, interpersonal dimension, as if writer and reader were in face-to-face conversation. It is presumably intended to appear candid, to disarm the reader and mask the fact that the power of newspaper discourse to influence is substantially in one direction. In this respect, the increasing use of discourse participants may be part of a general 'democratisation' of media discourse posited by Fairclough (1994:98).

At the same time, an increase in the occurrence of discourse participants accords a correspondingly greater pride of place to an editor's pronouncements, while blurring the distinction between speaker and audience. It can therefore equally well be considered an anti-democratic trend, masquerading as democratisation. Ambiguity is fundamental, both with regard to news content and also with regard to the linguistic forms which facilitate this function. Prominent among these forms is discourse participant and The Sun's statistics show a decisive change in tactics, away from soapbox-style oratory and in the direction of more covert ideological dissemination. Where in 1991 a majority of discourse participants unambiguously referred to the paper itself, in 2008 less than one in six do so, while $84 \%$ employ ambiguity, referring to an imprecise group or community. The dissemination of ideology is therefore becoming less straightforward in The Sun and the reader may increasingly be left in the dark as to the referents of we. 
This lack of awareness on the part of readers, with respect to the significance of newspaper discourse, mirrors that of spoken interaction, reported in Eggins \& Slade (1997): 'Most interactants participate in micro-encounters quite unaware of their ideological/macro-structural implications... successful ideologies naturalize themselves' (1997:61).

Since news per se does not exist, any events or features may qualify as 'news' provided they pass a two-fold test: they must be able to a) capture attention and b) accommodate a statement of stance. Whether a particular moment is one of 'good' or 'bad' news is unimportant because both types can nudge our sense of community in the desired direction. 'Good' news means praise for the tribe (eg a British sports team or individual has gained acclaim), while 'bad' news permits of a cathartic cleansing. Both are 'newsworthy', not by virtue of being informative, but because they entertain us and reinforce the on-going cultural reproduction (Hawes, 2001:401).

'Reality' itself is arguably a sociolinguistic construct and a site of struggle rather than an empirically observable phenomenon. But our cohesion as a group depends on agreeing a position. Therefore, we must form alliances so that we have 'friends' and 'enemies', to identify with or against, as the case may be. Which precise alliance we form is insignificant in terms of the news, provided we can identify the members of our group. In other words, we define who we are in terms of similarity and difference. But The Sun, using discourse participants to play on writer visibility, is disguising its own view as something objective. By reducing writer visibility it is also encouraging the readers to imagine that the positions espoused are their own. This applies to both referent slippage and disguised discourse participants.

In Orwell's 'Nineteen Eighty-Four' Big Brother assumes the burden of deciding who are friends and enemies on behalf of his people. If we label his state as state A, there is always an ally, state B, and an enemy, state C. Big Brother may at times switch states $\mathrm{B}$ and $\mathrm{C}$ around, but this goes almost unnoticed. Thus the moral is that it matters little whether the similarities and differences are observable, or merely people's minds. If they perceive another group's 'word' to be different, that is sufficient. If The Sun, with the help of discourse participants, can so skilfully play on the simulated interactive dimension (including all its potential ambiguities) that readers become accustomed to the ploy and begin to believe the editor's opinions have somehow been agreed on between them, then the battle is won. Or, perhaps, it is lost.

\section{REFERENCES}

[1] Daneš, F. (1974). Functional sentence perspective and the organisation of the text. In F. Daneš (ed) Papers on functional sentence perspective. pp.106-128.

[2] Prague: Academia.

[3] Davies, F. (1990). Reading between the lines: thematic choice as a device for presenting writer viewpoint in academic discourse. ESPecialist 9(1/2). pp.173-200.

[4] Eggins, S. \& Slade, D. (1997). Analysing casual conversation. London: Cassell.

[5] Fairclough, N. (1994). Discourse and social change. Polity.

[6] Fairclough, N. (1995). Critical discourse analysis. Boston: Addison Wesley.

[7] Fairclough, N. (2001). Language and power. London: Longman.

[8] Halliday, M.A.K. (1985). An introduction to functional grammar. London: Arnold.

[9] Hawes, T.P. (2001). Thematisation in Sun and Times editorials. Unpublished doctoral dissertation, University of Liverpool, U.K.

[10] Hawes, T.P. (2010). Horror bodies: The disapproved of. Textual bodies / The Luminary (University of Lancaster), Vol. 2 (4.8.2010). pp.4-13.

[11] Hill, J. (2007). Crises of meaning: Personalist language ideology in US media discourse. In S. Johnson \& A. Ensslin (eds). Language in the media. pp.70-88. Continuum.

[12] Hodge, R. \& Kress, G. (2006). Social semiotics. Polity.

[13] Hoey, M. (1983). On the surface of discourse. London: George Allen and Unwin.

[14] Linton, M. (1995). Sun powered politics. The Guardian. 30.10.95. Media Section. pp. 14-16.

[15] Orwell, G. (1949). Nineteen eighty-four. A novel. London: Secker \& Warburg.

[16] Reah, D. (2002). The Language of newspapers. Routledge.

[17] Richardson, J. (2007). Analysing newspapers: An approach from critical discourse analysis. Palgrave MacMillan.

[18] Riley, P. (2007). Language, culture and identity. Continuum.

[19] Talbot, M., Atkinson, K. \& Atkinson, D. (2003). Language and power in the modern world. Edinburgh University Press. 